\title{
Advances in the application of Let-7 microRNAs in the diagnosis, treatment and prognosis of leukemia (Review)
}

\author{
HAO CHEN $^{1 *}$, JIEWEI WANG $^{2 *}$, HUAN WANG $^{1}$, JINGRU LIANG $^{1}$, \\ JINHUA DONG $^{1}$, HOUQIAO BAI ${ }^{3}$ and GUOSHENG JIANG ${ }^{1,4}$ \\ ${ }^{1}$ School of Life Science and Technology, Weifang Medical University, Weifang, Shandong 261053; \\ ${ }^{2}$ Department of Transfusion, Jinan Zhangqiu District Maternal and Child Health Care Hospital, Jinan, Shandong 250200; \\ ${ }^{3}$ Department of Hematology, The Affiliated Weihai Second Municipal Hospital of Qingdao University, \\ Weihai, Shandong 264200; ${ }^{4}$ Institute of Immunology and Biotechnology Transformation, \\ Binzhou Medical University, Yantai, Shandong 264000, P.R. China
}

Received July 6, 2021; Accepted October 18, 2021

DOI: $10.3892 / \mathrm{ol} .2021 .13119$

\begin{abstract}
The lethal-7 (Let-7) family of microRNAs (miRNAs) controls the process of development and differentiation, but is also related to the occurrence of tumors and a poor prognosis of patients with tumors. Thus, a more comprehensive exploration of its functions will provide further insights into these processes, and may promote the diagnosis and treatment of tumors. Leukemia is a type of progressive malignant disease, and its pathogenesis involves a variety of epigenetic factors. Amongst the several related epigenetic factors, the Let-7 miRNAs are an important family of molecules that play a crucial role in maintaining a variety of critical biological processes, including development, differentiation and proliferation. In the present study, the role of Let-7 as a tumor suppressor gene and oncogene is reviewed, and the complex regulatory functions of several Let-7 family members in different subtypes of leukemia are described. The current body of knowledge thus far indicates that Let-7 is not only a potential diagnostic and prognostic marker of leukemia, but also a potential therapeutic target for the treatment of affected patients, with particular potential when targeted by adjuvant
\end{abstract}

Correspondence to: Dr Houqiao Bai, Department of Hematology, The Affiliated Weihai Second Municipal Hospital of Qingdao University, 51 Guangming Road, Weihai, Shandong 264200, P.R. China

E-mail: baihq1976@sina.com

Professor Guosheng Jiang, School of Life Science and Technology, Weifang Medical University, 7166 Baotongxi Street, Weifang, Shandong 261053, P.R. China

E-mail: jianggsh@hotmail.com

${ }^{*}$ Contributed equally

Key words: Let-7 microRNAs, leukemia, tumor therapy, regulatory factors treatments alongside traditional treatment to improve their survival rate.

\section{Contents}

1. Introduction

2. Overview of Let-7

3. Expression and roles of Let-7 in AML

4. Expression and roles of Let-7 in ALL

5. Expression and roles of Let-7 in CML

6. Expression and roles of Let-7 in APL

7. Expression and roles of Let-7 in other types of leukemia

8. Application of Let-7 in the treatment of leukemia

9. Conclusions

\section{Introduction}

Leukemia is a progressive malignant disease that can be divided into two categories, acute leukemia and chronic leukemia, according to the degree of differentiation and the natural course of the disease. Acute leukemia can be divided into acute myeloid leukemia (AML) and acute lymphoblastic leukemia (ALL), and chronic leukemia can be divided into chronic myelogenous leukemia (CML) and chronic lymphocytic leukemia (CLL) (1). In addition, there are also certain rare subtypes of leukemia, such as prolymphocytic leukemia and hairy cell leukemia. Although there has been rapid progress in the understanding of the cellular and molecular etiology of leukemia, and numerous novel anticancer drugs and treatment strategies have been developed in the past few decades, the chemotherapy-based treatment methods used for each type of leukemia have remained the same. For example, AML is still primarily treated with a combination of cytarabine and anthracycline (2-4). In recent years, novel targeted therapeutic strategies, including monoclonal antibodies and small molecule inhibitors, have been extensively researched (5). However, to date, apart from the use of all-trans retinoic acid in acute 
promyelocytic leukemia (APL), no targeted therapy has been proven to be more effective than conventional therapies (6).

It is well established that, at present, the treatment of leukemia is primarily based on chemotherapy, sometimes combined with radiotherapy. However, chemotherapy often results in cytotoxic side effects, including immune and hematopoietic suppression, or cognitive dysfunction of the central nervous system (7-9). In view of the toxic effects of chemotherapy, there is an urgent need to discover novel and effective treatment methods or techniques. MicroRNAs (miRNAs/miRs) are small non-coding RNAs of 22 nucleotides (nts) in length; the entirety of nucleotides 1-22 of the lethal-7 (Let-7) RNAs are highly conserved across bilaterians (Fig. 1) (10). Regulation of the expression of several genes by miRNAs is essential for maintaining a balance in a variety of important biological processes, including development, differentiation and hematopoiesis $(11,12)$. Certain non-coding RNAs, particularly miRNAs, are potential biomarkers for monitoring the progression, recurrence and prognosis of patients with cancer or leukemia (13), and can participate in the bilateral communication between the tumor and surrounding cells (14). It has also been demonstrated that miRNAs may be used as oncogenes or tumor suppressor genes, which promote the malignant transformation of solid and hematological tumors, including AML $(15,16)$. In addition, miRNAs can also participate in the occurrence and development of other types of diseases, such as Alzheimer's disease, obesity and cancer (17). An increasing number of experimental results have shown that certain miRNAs are increasingly associated with cancer, and such miRNAs are often referred to as 'oncomiRs' (18). There is growing evidence to suggest that Let-7 shares characteristics with other miRNAs and can serve as a biomarker for the diagnosis and prognosis of leukemia, and even that it can be used as a potential target for its treatment (19). In the present review, the associations between the Let-7 family members and leukemia are summarized, with a particular focus on the roles of these members as biomarkers in diagnosis and prognosis, or as potential therapeutic targets for the treatment of leukemia.

\section{Overview of Let-7}

OncomiRs are miRNAs targeting mostly cancer hallmark genes, such as oncogenes or tumor suppressor genes, and are extensively associated with carcinogenesis (20). These oncomiRs are derived from tissues or from the circulation, and can be used as biomarkers to predict tumor development and outcome (21). The Let-7 family of miRNAs are a prime example of oncomiRs, as they act as tumor suppressors in several cell types (22), including breast (23) and lung (24) cancer cells. The first member of this family was discovered in Caenorhabditis elegans, where it was shown to serve as an important developmental regulator $(25,26)$. The role of Let- 7 in the development of cancer led to speculation that it was related to the occurrence of leukemia (27). Deletion of Let-7 was shown to promote the development of cancer through induction of its target oncogenes and stemness factors. Let-7 physiologically regulates several target genes related to cell cycle progression, proliferation, differentiation and cell signaling pathways. As such, it is usually classified as a tumor suppressor, as it can decrease the aggressiveness, as well as the chemical and radiation resistance of a cancer (28). There are a variety of mature Let-7 subtypes (29), and nine important members have been identified to date: Let-7a, Let-7b, Let7c, Let-7d, Let-7e, Let-7f, Let-7g, Let-7i and miR-98. Seed sequences are the nt 2-8 sequences in miRNAs that bind to target mRNA 3'-untranslated region (3'UTR), and they are negatively regulated by base pairing. Seed sequences are a major determinant of miRNA activity (30). Base pairing of nts 9-22 can also promote target repression, but non-seed base pairing is less restricted than seed pairing. Thus, the miRNA sequences of seed sequences nts 2-8 are the most evolutionarily conserved, while the miRNA sequences of non-seed nts are less conserved (10). Mature members of the Let-7 family possess the same 'seed sequence' and a slightly different 'non-seed sequence' region. Mature Let-7 usually negatively regulates the expression levels of target mRNAs through incomplete base pairing on the 3'UTR and thereby inhibits translation (31). For example, in current diagnostic methods for papillary thyroid cancer, chimeric antigen receptor Let-7 is a useful marker (32). Let-7 is the central regulator of energy homeostasis, and exhibits significant plasticity in the metabolic response to nutrient availability and physiological activity (33). Conversely, Let-7 may regulate the characteristics of leukemia stem cells by inhibiting self-renewal and promoting differentiation (34). Let-7 can directly or indirectly inhibit a variety of cell cycle oncogenes, such as c-Myc, Ras, high mobility group AT-hook 2 and lin-28 homolog B (lin28B) (35), and participate in the entire process of regulation of gene expression of these types of cycle regulators $(36,37)$. These findings suggest that Let-7 is a key regulator of cell cycle progression and differentiation. Therefore, Let-7 may serve as a potential candidate target for the treatment of leukemia.

\section{Expression and roles of Let-7 in AML}

miRNAs control the expression of several genes that are involved in the differentiation of normal hematopoietic stem cells (HSCs) and tumorigenesis, including p53, Cyclin D1, C-myc, $\beta$-catenin and Survivin (16). In the process of tumor progression, due to post-transcriptional regulation, miRNAs have been found to significantly affect the phenotype of tumor-associated macrophages (TAMs) through a variety of target genes and signaling pathways, such as the Wnt signaling pathway $(38,39)$, and the deregulation of miRNAs is prevalent in hematological malignancies. A comprehensive understanding of the role of miRNAs in the complex regulatory network of AML cells is a prerequisite for the development and use of miRNAs as targets for the treatment of leukemia (40). It has been shown that the changes in the expression of miR-29, miR-125, miR-142, miR-146 and miR-155 play an important role in the progression and pathogenesis of AML (41). The miR-125 family, including miR-125a/miR-99b/Let-7e, miR-125b-2/miR-99a/Let-7c-1 and $\mathrm{miR}-125 \mathrm{~b}-1 / \mathrm{miR} 100 /$ Let-7a-2, are located on human chromosomes 19, 21 and 11, respectively, and are involved in the self-renewal of HSCs and megakaryocyte-erythrocyte progenitor cells (42). Overexpression of miR-125 will promote the development of a myeloproliferative neoplasm-like phenotype, which will then develop into AML. As a member of the miR-125 family, Let-7 can bind to target mRNA and cause its degradation or interrupt its transcription (43). Since the 
Let-7 microRNA sequence conservation

\section{C.elegans UGAGGUAGUAGGUUGUAUAGUU}

\section{D.melanogaster UGAGGUAGUAGGUUGUAUAGU- \\ D.rerio UGAGGUAGUAGGUUGUAUAGUU}

M.musculus UGAGGUAGUAGGUUGUAUAGUU

H.sapiens UGAGGUAGUAGGUUGUAUAGUU

Consensus UGAGGUAGUAGGUUGUAUAGUu

Figure 1. Conservation of the Let-7 microRNA. Let-7, lethal 7.

transcriptional regulation of specific genes by Let-7 is essential in several normal developmental processes, Let-7 is highly expressed during embryogenesis and brain development, and remains at high levels in adult tissues (44). In addition, as Let-7 is known to regulate the fate of HSCs together with mir-99a/100, mir-125b-1/2 and LIN28B (45), it was not unexpected that abnormal expression of miRNA Let-7 was found to lead to defects of cell proliferation and differentiation of AML cells. In a study on a group of patients with intermediate-risk AML, it was shown that high Let-7a-2-3p expression could be used alone as a biomarker for the prognosis of patients with AML (46). In patients with cytogenetically normal-AML (CN-AML), elevated expression of Let-7a-2-3p was significantly associated with prolonged overall survival and event-free survival times (40). Furthermore, the prognostic value was confirmed in the European Leukemia Net genetic categories and validated in multivariate analyses of other known risk factors (44). Amongst the patients with high Let-7a-2-3p expression, FosB proto-oncogene AP-1 transcription factor subunit was a commonly upregulated gene, which has been shown to be a cofactor of the Jun proto-oncogene AP-1 transcription factor subunit family, and is involved in regulating proliferation or differentiation of leukemia cells (47). Further analysis (46) showed that high Let-7a-2-3p expression could be used as a good prognostic marker in patients with CN-AML independently or in combination with other risk factors, particularly in patients after stem cell transplantation. Therefore, Let-7a-2-3p could be used not only as a prognostic biomarker for evaluating treatment outcome, but also as a possible indicator to guide the choice of treatment strategy for stem cell transplantation of CN-AML. Another study (48) confirmed that Let-7a-2-3p was upregulated in primary cells of patients with AML, and that it could promote the transformation of normal hematopoietic cells into malignant cells in vivo or in vitro. It was also demonstrated that high Let-7a-2-3p expression can decrease the expression of Jun dimerization protein 2 and leukocyte immunoglobulin-like receptors (LILRA5/6 and LILRB2/3), and is associated with a poor prognosis in patients with AML with a normal karyotype (49). In addition, Let-7 interferes with the expression of tumor suppressor gene BCL2/Bak1, which can promote the proliferation and inhibit the apoptosis of AML cells (50). In a previous study, Let-7b expression was shown to be lower in the low-risk karyotype AML group and higher in the intermediate or high-risk karyotype AML group (51). The expression of Let-7 is also related to the drug resistance of leukemia; for example, miR-98 belongs to the Let-7 family, and the overexpression of miR-98 in drug-resistant cells significantly reversed drug resistance (52). It is speculated that miR-98 may be a potential approach to overcome the drug resistance of leukemia cells. In addition to this, Let-7 was shown to be involved in the transformation of malignant AML in animal models, suggesting that Let-7 may be a therapeutic target with potential clinical value (53). Therefore, a comprehensive understanding of the carcinogenic events associated with changes in Let-7 expression and the regulatory network of downstream signaling pathways will not only help reveal its role in the occurrence and development of AML, but also provide a basis for Let-7-targeted therapeutic strategies.

\section{Expression and roles of Let-7 in ALL}

ALL accounts for $75 \%$ of childhood leukemias and $30 \%$ of childhood malignant tumors. Although intensive combination therapy can improve the therapeutic outcomes, 15-20\% of patients still fail to respond appropriately, and relapse is the primary cause of treatment failure (54). After initially understanding the relationship between the Let-7 family and AML, the role of the family in ALL was next determined. It was first discovered that Let-7b was one of 27 miRNAs differentially expressed between ALL and AML, and certain important miRNAs could distinguish ALL from AML more accurately (55). Let-7b was detected using reverse transcription-quantitative PCR in 70 patients with newly diagnosed pediatric ALL and the significance of Let-7b was evaluated in all the indicated patients (56). The results revealed that the expression levels of Let-7b in the patients varied only to a small degree compared with that in the healthy controls, with no statistically significant differences. Conversely, other reports confirmed that the expression of Let-7e was decreased in pediatric patients with ALL $(57,58)$, but that after 14 days of treatment, Let-7e expression was upregulated, and this was accompanied by the disappearance of minimal residual disease (58). Let-7i expression in ALL is rarely upregulated (59). Therefore, the aforementioned results indicated that the role of Let-7 family in ALL is complicated, and in order to better judge its role in the development of ALL, it is necessary to further adopt advanced quantitative or relative quantitative methods for the accurate determination of its biological activity (56). Compared with those in ALL, the expression levels of Let-7i in AML were reported to be upregulated, whereas Let-7e showed the opposite trend of expression. Although Let-7b is primarily used as one of the miRNA biomarkers for distinguishing ALL and AML (60), the role and application of the Let-7 family in ALL requires further large-scale analysis to evaluate its clinical significance.

\section{Expression and roles of Let-7 in CML}

Since the turn of the millennia, by studying a novel type of gene product of miRNAs in CML, it has been discovered that several miRNAs are dysregulated in patients with CML (61). It has been demonstrated that the pathogenesis and progression of CML is closely associated with the MAPK signaling pathway, and the dynamic reduction in miRNAs is primarily 


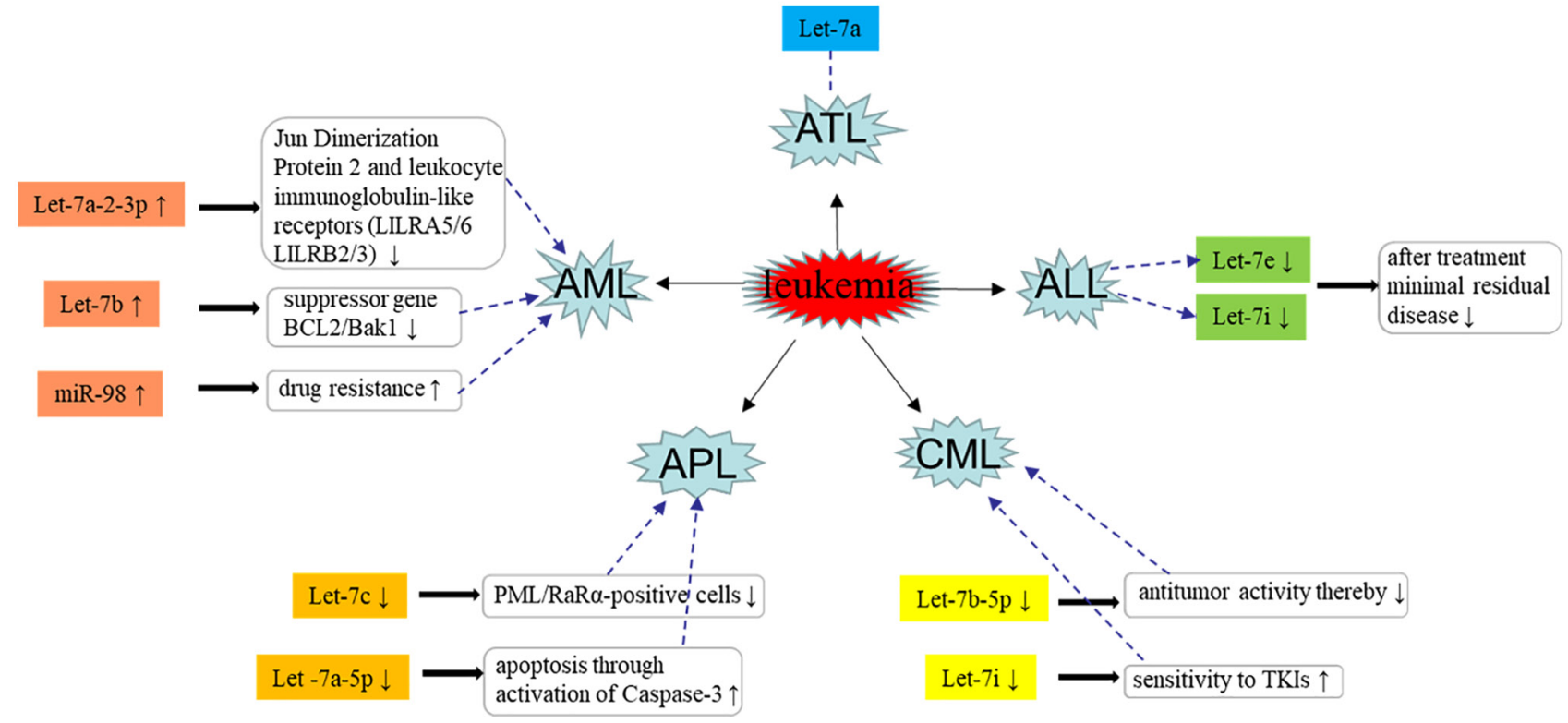

Figure 2. Different types of Let-7 miRNAs affect the occurrence and development of leukemia by regulating different pathways through positive and negative feedback. miRNA, microRNA; ATL, adult T-cell leukemia; ALL, acute lymphoblastic leukemia; CML chronic myeloid leukemia; APL, acute promyelocytic leukemia; AML, acute myeloid leukemia; Let-7, lethal 7; TKI, tyrosine kinase inhibitor; LILR, leukocyte immunoglobulin-like receptors; PML/RAR $\alpha$, promyelocytic leukemia/retinoic acid receptor $\alpha$.

involved in the PI3K/Akt signaling pathway (62); it was further shown that miRNAs can target multiple genes to regulate their expression (63). With the advent of advanced technologies and analytical methods, the downregulation of Let-7 in lung tumor samples was reported for the first time, paving the way for the use of miRNAs with high clinical potential as biomarkers for deferent tumors or leukemias (64). Microarrays were used to identify differentially expressed Let-7, and the expression profile and possible biological functions of plasma Let-7 in the different stages of CML were detected (65). The candidate miRNAs in the chronic phase, accelerated phase and explosive crisis phase were verified using reverse transcription-quantitative PCR assay, and the function of Let-7 was analyzed using the bioinformatics tool, Database for Annotation, Visualization and Integrated Discovery (66). The results showed that the dysregulation of Let-7 and its possible target genes were involved in important signaling pathways and related to changes in cell biological function. For example, plasma Let-7b-5p expression in patients with CML was lower, suggesting that the dysregulation of plasma Let-7 may play a regulatory role in the pathogenesis of CML. Let-7b-5p can be used as a potential biomarker for the diagnosis and prognosis of CML. This strong evidence showed the central role of Let-7 expression in tumorigenesis, and confirmed the regular characteristics of miRNAs in leukemia. In view of the higher rate of relapse in patients with CML, it is necessary to explore novel biomarkers for CML diagnosis, prognosis and treatment. The discovery of non-coding RNA Let-7 opens up novel prospects for the diagnosis, prognosis and treatment of CML $(67,68)$.

\section{Expression and roles of Let-7 in APL}

APL is a type of acute leukemia with rapid onset symptoms, insufficiency of intravascular coagulation, a poor response to chemotherapy and a high mortality rate. The most common

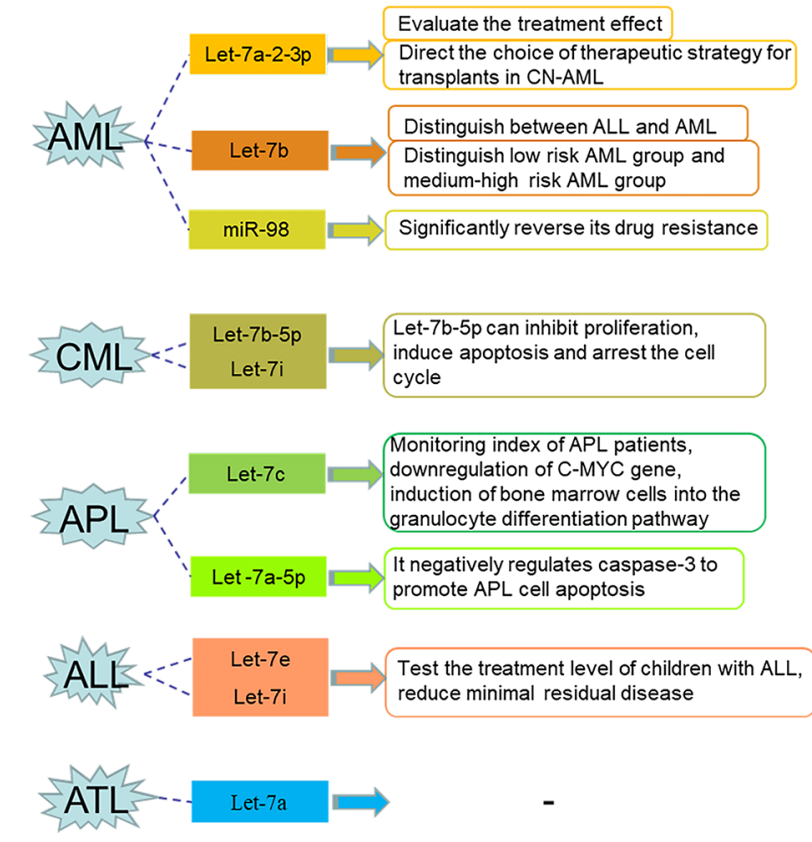

Figure 3. Diagnostic and prognostic value of Let-7 miRNAs. miRNA, microRNA; ATL, adult T-cell leukemia; ALL, acute lymphoblastic leukemia; CML, chronic myeloid leukemia; APL, acute promyelocytic leukemia; AML, acute myeloid leukemia; CN, cytogenetically normal; IGF1R, insulin-like growth factor 1 receptor; Let-7, lethal 7; -, no research data.

cause of APL is attributed to the promyelocytic leukemia/retinoic acid receptor $\alpha$ (PML/RAR $\alpha$ ) fusion gene by translocation of human chromosomes 15 and 17. Although there are several studies on the development of APL, the mechanism of pathogenesis of this leukemia is still not fully understood. The latest advances in molecular biology indicated that miRNAs were involved in the occurrence of APL by regulating the expression 
Table I. Modes of leukemia regulation, cellular effects, and diagnostic and prognostic value of different Let-7 family members.

\begin{tabular}{|c|c|c|c|c|c|}
\hline Let-7 member & Leukemia type & $\begin{array}{l}\text { Change in } \\
\text { expression }\end{array}$ & $\begin{array}{l}\text { Effect on } \\
\text { tumor cells }\end{array}$ & $\begin{array}{c}\text { Clinical } \\
\text { value/function }\end{array}$ & (Refs.) \\
\hline Let-7a-2-3p & IR-AML & Increased & Promotion & $\begin{array}{l}\text { Used alone as a biomarker } \\
\text { of prognosis in patients } \\
\text { with AML }\end{array}$ & (44) \\
\hline Let-7a-2-3p & CN-AML & Increased & Promotion & $\begin{array}{l}\text { Associated with a poor } \\
\text { prognosis in patients } \\
\text { with } \mathrm{CN}-\mathrm{AML}\end{array}$ & (49) \\
\hline Let-7b & $\begin{array}{l}\text { IR-AML and } \\
\text { HR-AML }\end{array}$ & Increased & Promotion & $\begin{array}{l}\text { Indicator to distinguish } \\
\text { ALL from AML }\end{array}$ & $(51)$ \\
\hline miR-98 & AML & Increased & Inhibition & $\begin{array}{l}\text { Overcomes AML cell } \\
\text { resistance }\end{array}$ & (53) \\
\hline Let-7e & ALL & $\begin{array}{l}\text { Decreased initially, } \\
\text { increased after } \\
\text { treatment }\end{array}$ & Inhibition & $\begin{array}{l}\text { Monitor ALL treatment } \\
\text { levels }\end{array}$ & $(57,58)$ \\
\hline Let-7i & ALL & Decreased & Inhibition & $\begin{array}{l}\text { Monitor ALL treatment } \\
\text { levels }\end{array}$ & (59) \\
\hline Let- $7 b-5 p$ & CML & Decreased & Inhibition & $\begin{array}{l}\text { Important regulator of } \\
\text { the CML signaling } \\
\text { pathway }\end{array}$ & $(65)$ \\
\hline Let-7c & APL & $\begin{array}{l}\text { Decreased initially, } \\
\text { increased after } \\
\text { relapse }\end{array}$ & Inhibition & $\begin{array}{l}\text { Predicts drug response or } \\
\text { relapse in the treatment } \\
\text { of APL }\end{array}$ & (77) \\
\hline Let $-7 a-5 p$ & APL & Decreased & Inhibition & $\begin{array}{l}\text { Negatively regulates } \\
\text { caspase } 3 \text { to promote } \\
\text { apoptosis in APL cells }\end{array}$ & (79) \\
\hline Let-7a & ATL & - & - & - & $(81)$ \\
\hline
\end{tabular}

ATL, adult T-cell leukemia; ALL, acute lymphoblastic leukemia; CML chronic myeloid leukemia; APL, acute promyelocytic leukemia; AML, acute myeloid leukemia; IR, intermediate-risk; HR, high-risk; CN, cytogenetically normal; miR, microRNA; Let-7, lethal 7; -, no research data.

of certain genes (69). For example, the proto-oncogene c-Myc is known to promote cell viability and proliferation, and plays a key role in maintaining the cell cycle in the majority of hematopoietic cell lines (70). In several malignant tumors of the hematopoietic system, the high expression of c-Myc is associated with a poor prognosis, and c-Myc is often activated by PML/RAR $\alpha$ in APL (71,72). Data from in vitro and in vivo models suggest that the downregulation of c-Myc expression induces myeloid cells to enter the granulocyte differentiation pathway (73). Failure to downregulate c-Myc in transgenic mice can lead to myeloid leukemia, which is characterized by blocked differentiation, indicating that the inhibition of c-Myc is a key event for cells to commit to the differentiation pathway $(74,75)$. The Let-7 family members may regulate the levels of c-Myc and play a key role in the balance between the differentiation and proliferation of leukemia cells (76). Recently, it has been found that the level of Let-7c in PML/RAR $\alpha$-positive cells in patients with APL is lower than that of normal promyelocytic granulocytes, and that the reduced level of Let-7c promotes the granulocyte differentiation of AML cell lines and primitive cells (77). The level of Let-7c is directly affected by chemotherapy or other treatments, and its level increases in leukemia cells following chemotherapy and decreases again after recurrence (78). Therefore, monitoring Let-7 levels can be used to predict drug response or recurrence in the treatment of APL. As for the diagnostic value of changes in Let-7 levels in the blood and urine, this aspect remains to be comprehensively assessed. Let-7c can be used as a regulatory factor to mediate the development of APL, play an important role in the initiation and progression of the disease and also be used as an important target its treatment (57). Furthermore, it was shown that downregulation of Let-7a-5p significantly increased the rate of apoptosis or necrosis of HL60 cells (79). Blockade of Let-7a-5p decreases the cellular viability of HL60 cell lines, partly due to induction of apoptosis through activation of caspase-3. Therefore, blockade of Let-7a-5p in APL and negative regulation of caspase- 3 to promote apoptosis in APL cells may also be a novel therapeutic strategy.

\section{Expression and roles of Let-7 in other types of leukemia}

In addition to the effects of the Let-7 miRNA family in the aforementioned types of leukemia, the family is differentially expressed in monocytes, lymphocytes, neutrophils and 
reticulocytes in the adult blood. It is worth noting that Let-7a and Let-7b are primarily expressed in all peripheral blood cells (80). The Let-7 family has also been observed in adult T-cell leukemia (81), and the latest research has found that Let-7c inhibits cell proliferation, migration and invasion, and induces the $\mathrm{G}_{1}$ arrest and apoptosis of LIHC cells (82). However, current research has not yet found the role of Let-7 family in CLL and other types of leukemia. As some cytokines have been reported to affect the proliferation of CLL cells in vivo, such as nuclear RNAs, they can be used as epigenetic regulators and targets (83); therefore, the alterations to the cytokine balance by miRNA Let-7 may regulate cell proliferation and apoptosis (84). The changes in the levels of various Let-7 members in the different types of leukemia and their effects are summarized in Fig 2. With an ever-growing understanding of the biological role of miRNAs in the pathogenesis of hematological malignancies, it is hypothesized that other regulatory factors will also be discovered and used to treat leukemia.

\section{Application of Let-7 in the treatment of leukemia}

As aforementioned, there is increasing evidence that the Let-7 family members are not only involved in the occurrence and development of leukemia, but are also related to its prognosis, and exhibit attractive potential in the treatment, diagnosis and prognostic of leukemia (Fig. 3). The present review focuses on the roles of the Let- 7 members in the treatment of leukemia, highlighting them as an alternative treatment approach. Recent advances in genetic engineering have allowed for the generation of miRNA mimics, or artificial structures of RNA double strands that are identical to mature miRNA sequences. miRNA mimics have been designed to possess endogenous miRNA functions, allowing them to function as tumor suppressors/promoters (85). Certain types of miRNA mimic have been used in medicine as therapeutic agents loaded on the surface of targeted drugs, which provide an important option for Let-7 as a novel target for therapy or to induce the reversal of drug resistance. Different members of the Let-7 family play important regulatory roles in various types of leukemia, and modulation of these can be translated into therapeutic strategies for leukemia. However, miRNAs, including Let-7, act not only in cancer cells, but also in normal cells (86). Therefore, systemic mimicry of miRNA administration may cause unexpected side effects and there are still several problems to overcome for safe clinical application (27). When considering the therapeutic potential of Let-7, the influence of Let-7 changes on the immune system in vivo should also be considered, such as the influence of some transcriptional regulatory factors of miRNA, miRNA processing enzymes and factors related to target gene therapy on the intercellular communication pathways (87). Combined with the aforementioned factors, a safe treatment strategy that incorporates miRNA Let-7 may be developed. In order to develop efficient and safe treatment methods exploiting miRNA Let-7, a suitable drug delivery system is also one of the key points that requires attention. For example, the heterogeneous delivery system of nanoparticle miRNAs has been widely studied, including in vivo and in clinical trials (88). Furthermore, as the Let-7 members are closely associated with the immune system, the effects on the immune function of patients treated with Let-7 target therapy should also be evaluated.

\section{Conclusions}

There is growing evidence indicating that the Let-7 members are aberrantly expressed in various types of leukemias, and that they can serve as markers for diagnosis, progression, therapeutic response and clinical outcome (Table I). A comprehensive understanding of the complete regulatory network of oncogenic events and downstream signaling pathways by Let-7 will not only assist in the understanding of their role in AML development and progression, but also provide a basis for the corresponding therapeutic strategies. Recent research advances have provided more details on how the deregulation of Let-7 leads to leukemogenesis and progression. However, additional in vivo and in vitro models, as well as clinical studies, are required to further investigate a safe and effective therapeutic regimen for leukemia treatment. Thus, the Let-7 family members are very attractive biomarkers and/or therapeutic targets for the management of leukemia; however, several difficult challenges remain to be solved before they can be recommended for clinical application.

\section{Acknowledgements}

Not applicable.

\section{Funding}

This study was supported by The National 12th Five-Year Plan for Major New Drug Creation Science and Technology (grant no. 2013ZX09103003-002), the National 13th Five-Year Plan for Major New Drug Creation Science and Technology (grant no. 2019ZX09301-166), the National Natural Science Foundation of China (grant nos. 81101605 and 81573467), the Natural Science Foundation of Shandong (grant no. ZR2020QH160) and The Foundation for Teachers' Research Project of Jining Medical University (grant no. JYFC2019FKJ102).

\section{Availability of data and materials}

Not applicable.

\section{Authors' contributions}

HC was involved in the conceptualization and methodology of this study, and in the writing and preparation of the original manuscript, as well as the review and editing of the final version. JW, HW and JL were involved in the discussion of the study methodology and the review and editing of the original manuscript. JD and HB were involved in the data analysis and the review and editing of the manuscript. GJ was involved in the conceptualization, supervision and methodology of the study, as well as the writing and preparation of the first draft, and the review and editing of the original manuscript. All authors have read and approved the manuscript. Data authentication is not applicable. 


\section{Ethics approval and consent to participate}

Not applicable.

\section{Patient consent for publication}

Not applicable.

\section{Competing interests}

The authors declare that they have no competing interests.

\section{References}

1. Hanahan D and Weinberg RA: Hallmarks of cancer: The next generation. Cell 144: 646-674, 2011.

2. Pelcovits A and Niroula R: Acute myeloid leukemia: A review. R I Med J (2013) 103: 38-40, 2020.

3. Burnett A, Wetzler M and Löwenberg B: Therapeutic advances in acute myeloid leukemia. J Clin Oncol 29: 487-494, 2011.

4. Llave C, Xie Z, Kasschau KD and Carrington JC: Cleavage of scarecrow-like mRNA targets directed by a class of Arabidopsis miRNA. Science 297: 2053-2056, 2002.

5. Ciardiello F and Tortora G: A novel approach in the treatment of cancer: Targeting the epidermal growth factor receptor. Clin Cancer Res 7: 2958-2970, 2001.

6. Hattori M: Finishing the euchromatic sequence of the human genome. Tanpakushitsu Kakusan Koso 50: 162-168, 2005 (In Japanese).

7. Hunger SP and Mullighan CG: Acute lymphoblastic leukemia in children. N Engl J Med 373: 1541-1552, 2015.

8. Mavrea K, Efthymiou V, Katsibardi K, Tsarouhas K, Kanaka-Gantenbein C, Spandidos DA, Chrousos G, Kattamis A and Bacopoulou F: Cognitive function of children and adolescent survivors of acute lymphoblastic leukemia: A meta-analysis. Oncol Lett 21: 262, 2021.

9. Pääkkö E, Harila-Saari A, Vanionpää L, Himanen S, Pyhtinen J and Lanning M: White matter changes on MRI during treatment in children with acute lymphoblastic leukemia: Correlation with neuropsychological findings. Med Pediatr Oncol 35: 456-461, 2000.

10. Nelson C and Ambros V: A cohort of caenorhabditis species lacking the highly conserved let-7 microRNA. G3 (Bethesda) 11 jkab022, 2021.

11. Siomi H and Siomi MC: Posttranscriptional regulation of microRNA biogenesis in animals. Mol Cell 38: 323-332, 2010.

12. Jiang X, Huang H, Li Z, Li Y, Wang X, Gurbuxani S, Chen P, He C, You D, Zhang S, et al: Blockade of miR-150 maturation by MLL-fusion/MYC/LIN-28 is required for MLL-associated leukemia. Cancer Cell 22: 524-535, 2012.

13. Agostini M, Ganini C, Candi E and Melino G: The role of noncoding RNAs in epithelial cancer. Cell Death Discov 6: 13, 2020.

14. Virga F, Quirico L, Cucinelli S, Mazzone M, Taverna D and Orso F: MicroRNA-mediated metabolic shaping of the tumor microenvironment. Cancers (Basel) 13: 127, 2021.

15. Lan FF, Wang H, Chen YC, Chan CY, Ng SS, Li K, Xie D, He ML, Lin MC and Kung HF: Hsa-let-7g inhibits proliferation of hepatocellular carcinoma cells by downregulation of c-Myc and upregulation of p16(INK4A). Int J Cancer 128: 319-331, 2011.

16. Viswanathan SR and Daley GQ: Lin28: A microRNA regulator with a macro role. Cell 140: 445-449, 2010.

17. Conti I, Varano G, Simioni C, Laface I, Milani D, Rimondi E and Neri LM: miRNAs as influencers of cell-cell communication in tumor microenvironment. Cells 9: 220, 2020.

18. Linck-Paulus L, Hellerbrand C, Bosserhoff AK and Dietrich P. Dissimilar appearances are deceptive-common microRNAs and therapeutic strategies in liver cancer and melanoma. Cells 9: 114 2020.

19. Trino S, Lamorte D, Caivano A, Laurenzana I, Tagliaferri D, Falco G, Del Vecchio L, Musto P and De Luca L: MicroRNAs as new biomarkers for diagnosis and prognosis, and as potential therapeutic targets in acute myeloid leukemia. Int J Mol Sci 19 : $460,2018$.
20. Wong NW, Chen Y, Chen S and Wang X: OncomiR: An online resource for exploring pan-cancer microRNA dysregulation. Bioinformatics 34: 713-715, 2018.

21. Villanueva A, Hoshida Y, Toffanin S, Lachenmayer A, Alsinet C, Savic R, Cornella $\mathrm{H}$ and Llovet JM: New strategies in hepatocellular carcinoma: Genomic prognostic markers. Clin Cancer Res 16: 4688-4694, 2010.

22. Reinhart BJ, Slack FJ, Basson M, Pasquinelli AE, Bettinger JC, Rougvie AE, Horvitz HR and Ruvkun G: The 21-nucleotide let-7 RNA regulates developmental timing in Caenorhabditis elegans. Nature 403: 901-906, 2000.

23. Bozgeyik E: Bioinformatic analysis and in vitro validation of Let-7b and Let-7c in breast cancer. Comput Biol Chem 84: 107191,2020

24. Lelli D, Pedone C, Majeed M and Sahebkar A: Curcumin and lung cancer: The role of microRNAs. Curr Pharm Des 23: 3440-3444, 2017.

25. Rougvie AE: Control of developmental timing in animals. Nat Rev Genet 2: 690-701, 2001.

26. Ambros V: microRNAs: Tiny regulators with great potential. Cell 107: 823-826, 2001

27. Büssing I, Slack FJ and Grosshans H: let-7 microRNAs in development, stem cells and cancer. Trends Mol Med 14: 400-409, 2008.

28. Nimmo RA and Slack FJ: An elegant miRror: microRNAs in stem cells, developmental timing and cancer. Chromosoma 118: 405-418, 2009

29. Roush S and Slack FJ: The let-7 family of microRNAs. Trends Cell Biol 18: 505-516, 2008.

30. Brancati G and Großhans H: An interplay of miRNA abundance and target site architecture determines miRNA activity and specificity. Nucleic Acids Res 46: 3259-3269, 2018.

31. Hammond SM: An overview of microRNAs. Adv Drug Deliv Rev 87: 3-14, 2015

32. Perdas E, Stawski R, Kaczka K and Zubrzycka M: Analysis of Let-7 family miRNA in plasma as potential predictive biomarkers of diagnosis for papillary thyroid cancer. Diagnostics (Basel) 10: 130, 2020.

33. Jiang S: A regulator of metabolic reprogramming: MicroRNA Let-7. Transl Oncol 12: 1005-1013, 2019.

34. Powers JT, Tsanov KM, Pearson DS, Roels F, Spina CS, Ebright R, Seligson M, de Soysa Y, Cahan P, Theißen J, et al: Multiple mechanisms disrupt the let-7 microRNA family in neuroblastoma. Nature 535: 246-251, 2016.

35. Wang T, Wang G, Hao D, Liu X, Wang D, Ning N and Li X: Aberrant regulation of the LIN28A/LIN28B and let-7 loop in human malignant tumors and its effects on the hallmarks of cancer. Mol Cancer 14: 125, 2015.

36. Vignali R and Marracci S: HMGA genes and proteins in development and evolution. Int J Mol Sci 21: 654, 2020.

37. Chae HJ, Seo JB, Kim SH, Jeon YJ and Suh SS: Fhit induces the reciprocal suppressions between Lin28/Let-7 and miR-17/92miR. Int J Med Sci 18: 706-714, 2021.

38. Chen C, Liu JM and Luo YP: MicroRNAs in tumor immunity: Functional regulation in tumor-associated macrophages. J Zhejiang Univ Sci B 21: 12-28, 2020.

39. Sun JD, Li XM, Liu JL, Li J and Zhou H: Effects of miR-150-5p on cerebral infarction rats by regulating the Wnt signaling pathway via p53. Eur Rev Med Pharmacol Sci 24: 3882-3891, 2020.

40. Jia Y and Wei Y: Modulators of MicroRNA function in the immune system. Int J Mol Sci 21: 2357, 2020.

41. Khalaj M, Tavakkoli M, Stranahan AW and Park CY: Pathogenic microRNA's in myeloid malignancies. Front Genet 5: 361, 2014.

42. Shaham L, Binder V, Gefen N, Borkhardt A and Izraeli S: MiR-125 in normal and malignant hematopoiesis. Leukemia 26: 2011-2018, 2012.

43. Kim VN: Small RNAs: Classification, biogenesis, and function Mol Cells 19: 1-15, 2005.

44. Jinlong S, Lin F, Yonghui L, Li Y and Weidong W: Identification of let-7a-2-3p or/and miR-188-5p as prognostic biomarkers in cytogenetically normal acute myeloid leukemia. PLoS One 10: $\mathrm{e} 0118099,2015$.

45. Lee H, Han S, Kwon CS and Lee D: Biogenesis and regulation of the let-7 miRNAs and their functional implications. Protein Cell 7: 100-113, 2016.

46. Emmrich S, Rasche M, Schöning J, Reimer C, Keihani S, Maroz A, Xie Y, Li Z, Schambach A, Reinhardt D and Klusmann JH: miR-99a/100 125b tricistrons regulate hematopoietic stem and progenitor cell homeostasis by shifting the balance between TGF $\beta$ and Wnt signaling. Genes Dev 28: 858-874, 2014. 
47. Chen Y, Chen S, Lu J, Yuan D, He L, Qin P, Tan H and Xu L: MicroRNA-363-3p promote the development of acute myeloid leukemia with RUNX1 mutation by targeting SPRYD4 and FNDC3B. Medicine (Baltimore) 100: e25807, 2021.

48. Ha Sen Ta Na, Nuo M, Meng QT and Xia ZY: The pathway of Let-7a-1/2-3p and HMGB1 mediated dexmedetomidine inhibiting microglia activation in spinal cord ischemia-reperfusion injury mice. J Mol Neurosci 69: 106-114, 2019.

49. Zhang H, Luo XQ, Feng DD, Zhang XJ, Wu J, Zheng YS, Chen X, $\mathrm{Xu} \mathrm{L}$ and Chen YQ: Upregulation of microRNA-125b contributes to leukemogenesis and increases drug resistance in pediatric acute promyelocytic leukemia. Mol Cancer 10: 108, 2011.

50. Ward E, DeSantis C, Robbins A, Kohler B and Jemal A: Childhood and adolescent cancer statistics, 2014. CA Cancer J Clin 64: 83-103, 2014.

51. Liao Q, Wang B, Li X and Jiang G: miRNAs in acute myeloid leukemia. Oncotarget 8: 3666-3682, 2017.

52. Wang X, Zhang G, Cheng Z, Dai L, Jia L, Jing X, Wang H, Zhang R, Liu M, Jiang T, et al: Knockdown of lncRNA ANRIL inhibits the development of cisplatin resistance by upregulating miR-98 in lung cancer cells. Oncol Rep 44: 1025-1036, 2020

53. Huang Y, Hong X, Hu J and Lu Q: Targeted regulation of MiR-98 on E2F1 increases chemosensitivity of leukemia cells K562/A02. Onco Targets Ther 10: 3233-3239, 2017

54. Kato $\mathrm{M}$ and Manabe A: Treatment and biology of pediatric acute lymphoblastic leukemia. Pediatr Int 60: 4-12, 2018.

55. Mi S, Lu J, Sun M, Li Z, Zhang H, Neilly MB, Wang Y, Qian Z, Jin J, Zhang Y, et al: MicroRNA expression signatures accurately discriminate acute lymphoblastic leukemia from acute myeloid leukemia. Proc Natl Acad Sci USA 104: 19971-19976, 2007.

56. Shafik RE, Abd El Wahab N, Senoun SA, Ebeid E and El Taweel MA: Expression of Micro-RNA 128 and Let-7b in pediatric acute lymphoblastic leukemia cases. Asian Pac J Cancer Prev 19: 2263-2267, 2018.

57. Schotte D, Chau JC, Sylvester G, Liu G, Chen C, van der Velden VH, Broekhuis MJ, Peters TC, Pieters R and den Boer ML: Identification of new microRNA genes and aberrant microRNA profiles in childhood acute lymphoblastic leukemia. Leukemia 23: 313-322, 2009

58. de Oliveira JC, Scrideli CA, Brassesco MS, Morales AG, Pezuk JA, Queiroz Rde P, Yunes JA, Brandalise SR and Tone LG: Differential miRNA expression in childhood acute lymphoblastic leukemia and association with clinical and biological features. Leuk Res 36: 293-298, 2012.

59. Zhang H, Luo XQ, Zhang P, Huang LB, Zheng YS, Wu J, Zhou H $\mathrm{Qu} \mathrm{LH}, \mathrm{Xu} \mathrm{L}$ and Chen YQ: MicroRNA patterns associated with clinical prognostic parameters and CNS relapse prediction in pediatric acute leukemia. PLoS One 4: e7826, 2009.

60. Lieberman J: Tapping the RNA world for therapeutics. Nat Struct Mol Biol 25: 357-364, 2018.

61. Calin GA, Dumitru CD, Shimizu M, Bichi R, Zupo S, Noch E, Aldler H, Rattan S, Keating M, Rai K, et al: Frequent deletions and down-regulation of micro-RNA genes miR15 and miR16 at 13 q14 in chronic lymphocytic leukemia. Proc Natl Acad Sci USA 99: 15524-15529, 2002

62. He L, Thomson JM, Hemann MT, Hernando-Monge E, Mu D, Goodson S, Powers S, Cordon-Cardo C, Lowe SW, Hannon GJ and Hammond SM: A microRNA polycistron as a potential human oncogene. Nature 435: 828-833, 2005

63. Lewis BP, Shih IH, Jones-Rhoades MW, Bartel DP and Burge CB Prediction of mammalian microRNA targets. Cell 115: 787-798, 2003.

64. Takamizawa J, Konishi H, Yanagisawa K, Tomida S, Osada H, Endoh H, Harano T, Yatabe Y, Nagino M, Nimura Y, et al: Reduced expression of the let-7 microRNAs in human lung cancers in association with shortened postoperative survival. Cancer Res 64: 3753-3756, 2004.

65. Zhang J, Jiang Y, Han X, Roy M, Liu W, Zhao X and Liu J: Differential expression profiles and functional analysis of plasma miRNAs associated with chronic myeloid leukemia phases. Future Oncol 15: 763-776, 2019.

66. Dennis G Jr, Sherman BT, Hosack DA, Yang J, Gao W, Lane HC and Lempicki RA: DAVID: Database for annotation, visualization, and integrated discovery. Genome Biol 4: P3, 2003.

67. Ma L, Teruya-Feldstein J and Weinberg RA: Tumour invasion and metastasis initiated by microRNA-10b in breast cancer. Nature 449: 682-688, 2007.
68. Mitchell PS, Parkin RK, Kroh EM, Fritz BR, Wyman SK, Pogosova-Agadjanyan EL, Peterson A, Noteboom J, O'Briant KC, Allen A, et al: Circulating microRNAs as stable blood-based markers for cancer detection. Proc Natl Acad Sci USA 105: 10513-10518, 2008

69. Ding Y, Wang ZC, Zheng Y, Hu Z, Li Y, Luo DF and Wang SY: C-Myc functions as a competing endogenous RNA in acute promyelocytic leukemia. Oncotarget 7: 56422-56430, 2016.

70. Delgado MD and León J: Myc roles in hematopoiesis and leukemia. Genes Cancer 1: 605-616, 2010.

71. Nesbit CE, Tersak JM and Prochownik EV: MYC oncogenes and human neoplastic disease. Oncogene 18: 3004-3016, 1999.

72. Müller-Tidow C, Steffen B, Cauvet T, Tickenbrock L, Ji P, Diederichs S, Sargin B, Köhler G, Stelljes M, Puccetti E, et al: Translocation products in acute myeloid leukemia activate the Wnt signaling pathway in hematopoietic cells. Mol Cell Biol 24: 2890-2904, 2004.

73. Hoffman B and Liebermann DA: Apoptotic signaling by c-MYC. Oncogene 27: 6462-6472, 2008.

74. Johansen LM, Iwama A, Lodie TA, Sasaki K, Felsher DW, Golub TR and Tenen DG: c-Myc is a critical target for c/EBPalpha in granulopoiesis. Mol Cell Biol 21: 3789-3806, 2001.

75. Felsher DW and Bishop JM: Reversible tumorigenesis by MYC in hematopoietic lineages. Mol Cell 4: 199-207, 1999.

76. Li T, Huang Y, Zhou W and Yan Q: Let-7c-3p regulates autophagy under oxidative stress by targeting ATG3 in lens epithelial cells. Biomed Res Int 2020: 6069390, 2020.

77. Pelosi A, Careccia S, Lulli V, Romania P, Marziali G, Testa U, Lavorgna S, Lo-Coco F, Petti MC, Calabretta B, et al: miRNA let-7c promotes granulocytic differentiation in acute myeloid leukemia. Oncogene 32: 3648-3654, 2013.

78. Karreth FA, Tay Y, Perna D, Ala U, Tan SM, Rust AG, DeNicola G, Webster KA, Weiss D, Perez-Mancera PA, et al: In vivo identification of tumor-suppressive PTEN ceRNAs in an oncogenic BRAF-induced mouse model of melanoma. Cell 147: 382-395, 2011.

79. Fasihi-Ramandi M, Moridnia A, Najafi A and Sharifi M: Inducing apoptosis and decreasing cell proliferation in human acute promyelocytic leukemia through regulation expression of CASP3 by Let-7a-5p blockage. Indian J Hematol Blood Transfus 34: 70-77, 2018.

80. Wang W, Corrigan-Cummins M, Barber EA, Saleh LM, Zingone A, Ghafoor A, Costello R, Zhang Y, Kurlander RJ, Korde N, et al: Aberrant levels of miRNAs in bone marrow microenvironment and peripheral blood of myeloma patients and disease progression. J Mol Diagn 17: 669-678, 2015.

81. Liu Y, Cheng Z, Pang Y, Cui L, Qian T, Quan L, Zhao H, Shi J, Ke X and Fu L: Role of microRNAs, circRNAs and long noncoding RNAs in acute myeloid leukemia. J Hematol Oncol 12: 51, 2019.

82. Li Y, Li P and Wang N: Effect of let-7c on the PI3K/Akt/FoxO signaling pathway in hepatocellular carcinoma. Oncol Lett 21: 96, 2021.

83. Yang X, Liu M, Li M, Zhang S, Hiju H, Sun J, Mao Z, Zheng M and Feng B: Epigenetic modulations of noncoding RNA: A novel dimension of cancer biology. Mol Cancer 19: 64, 2020.

84. Allegra A, Musolino C, Tonacci A, Pioggia G, Casciaro M and Gangemi S: Clinico-biological implications of modified levels of cytokines in chronic lymphocytic leukemia: A possible therapeutic role. Cancers (Basel) 12: 524, 2020.

85. Mauri C and Bosma A: Immune regulatory function of B cells Annu Rev Immunol 30: 221-241, 2012.

86. Bajan S and Hutvagner G: RNA-based therapeutics: From antisense oligonucleotides to miRNAs. Cells 9: 137, 2020.

87. Chakraborty C, Sharma AR, Sharma G and Lee SS: The interplay among miRNAs, major cytokines, and cancer-related inflammation. Mol Ther Nucleic Acids 20: 606-620, 2020.

88. Fernandez-Piñeiro I, Badiola I and Sanchez A: Nanocarriers for microRNA delivery in cancer medicine. Biotechnol Adv 35: 350-360, 2017.

This work is licensed under a Creative Commons Attribution-NonCommercial-NoDerivatives 4.0 International (CC BY-NC-ND 4.0) License. 